\title{
More automation and less cognitive control of imagined walking movements in high- versus low-fit older adults
}

\author{
Ben Godde* and Claudia Voelcker-Rehage \\ Neuroscience and Human Performance, Jacobs Center on Lifelong Learning, Jacobs University, Bremen, Germany
}

\section{Edited by:}

Lars Nyberg, Umeå University,

Sweden

Reviewed by:

Carl Johan Olsson, Umeå University,

Sweden

Lillemor Lundin-Olsson, Umeå

University, Sweden

*Correspondence:

Ben Godde, Neuroscience and Human Performance, Jacobs Center on

Lifelong Learning, Jacobs University,

Campus Ring 1, D-28759 Bremen,

Germany.

e-mail: b.godde@jacobs-university.de
Using motor imagery, we investigated brain activation in simple and complex walking tasks (walking forward and backward on a treadmill) and analyzed if the motor status of older adults influenced these activation patterns. Fifty-one older adults (64-79 years of age) were trained in motor execution and imagery and then performed the imagination task and two control tasks (standing, counting backward) in a horizontal position within a 3T MRI scanner (first-person perspective, eyes closed). Walking backward as compared to walking forward required larger activations in the primary motor cortex, supplementary motor area, parietal cortex, thalamus, putamen, and caudatum, but less activation in the cerebellum and brainstem. Motor high-fit individuals showed more activations and larger BOLD signals in motor-related areas compared to low-fit participants but demonstrated lower activity in the dorsolateral prefrontal cortex. Moreover, parietal activation in high-fit participants remained stable throughout the movement period whereas low-fit participants revealed an early drop in activity in this area accompanied by increasing activity in frontal brain regions. Overall, walking forward seemed to be more automated (more activation in cerebellum and brainstem), whereas walking backward required more resources, e.g., for visual-spatial processing and sensorimotor control. Low-fit subjects in particular seemed to require more cognitive resources for planning and controlling. High-fit subjects, on the contrary, revealed more movement automation and a higher "attention span." Our results support the hypothesis that high fitness corresponds with more automation and less cognitive control of complex motor tasks, which might help to free up cognitive resources.

\section{INTRODUCTION}

Compelling evidence has been accumulated about a strong relationship between bodily fitness and cognitive performance in old age (Dustman et al., 1994; Etnier et al., 1997; Colcombe and Kramer, 2003; Woo and Sharps, 2003; Kramer and Erickson, 2007; Hillman et al., 2008). Furthermore, it has been suggested that, with advances in age, motor aspects of performance are increasingly in need of cognitive control and supervision and that resource competition therefore leads to lower cognitive performance in older adults (for example, Kahnemann, 1973; Lindenberger et al., 2000). This has been demonstrated, for example, in relation to locomotor tasks like walking forward which seem to require cognitive control of gait and balance (Hausdorff et al., 2005; Yogev-Seligmann et al., 2008). A high level of motor fitness might be able to counteract cognitive decline during aging (Voelcker-Rehage et al., 2010) and might be able to reduce the cognitive resources expended to control a locomotor task. To address this assumption and to examine if high- and low-fit participants differ in the cortical resources expended on locomotion, we used motor imagery as a well accepted method to capture brain activity during the accomplishment of motor tasks (Miyai et al., 2001; Malouin et al., 2003; Jahn et al., 2004; La Fougère et al., 2010).

\section{RELATIONSHIP BETWEEN MOTOR AND COGNITIVE PERFORMANCE}

Several studies indicate a correlation between age-related declines in the sensory and motor system on the one hand and age-related declines in cognitive functioning on the other hand (Lindenberger and Baltes, 1994; Baltes and Lindenberger, 1997; Li and Lindenberger, 2002). Others report that gait and balance, in seemingly simple tasks such as routine walking, are rather complex motor tasks (Hausdorff et al., 2005) and require a large amount of higher-level cognitive input (Yogev-Seligmann et al., 2008). It has also been shown that forward and backward walking in older adults are generally characterized by a lower velocity, cadence, stride length, and swing phase and thus seem to be more difficult for older as compared to younger adults (Laufer, 2005).

Age is thought to be associated with reduced processing efficiency (e.g., decrease in nerve conduction speed, increased lateralization) (Hedden and Gabrieli, 2004) and in turn a decrease in cognitive performance such as diminished response time, working memory and the processing of multiple tasks. This occurs alongside an increased need for cognitive control and resources to perform a given cognitive or motor task (Baltes et al., 2006). With decreasing reserve capacity in older adults, these effects may become increasingly important and get especially apparent in so-called dual-task situations where subjects have to perform motor and cognitive tasks concurrently (Lindenberger et al., 2000; Voelcker-Rehage et al., 2006; VoelckerRehage and Alberts, 2007; Yogev-Seligmann et al., 2008). Several intervention studies have furthermore supported the connection between "body and mind," demonstrating the positive effects of fitness training on cognitive functioning and/or brain processing (Colcombe and Kramer, 2003; Colcombe et al., 2004; Hillman et al., 2008; Erickson and Kramer, 2009; Lustig et al., 2009). Whereas most 
of these studies focused on cardiovascular fitness (see reviews by Erickson and Kramer, 2009; Lustig et al., 2009), few studies have investigated the role of abilities like balance, speed or coordination for cognition in old age (Nieto et al., 2008; Flegal and Reuter-Lorenz, 2010). Our own studies have revealed that not only high physical fitness (muscle strength and cardiovascular fitness), but also high motor fitness (flexibility, coordination, balance, speed) is positively related to executive control and perceptual speed in older adults. Consequently, a higher fitness level or motor status, respectively, might be able to facilitate the execution of motor tasks and counteract cognitive decline during aging (Voelcker-Rehage et al., 2010).

\section{MOTOR IMAGERY}

Functional MRI provides a powerful approach in determining which cortical resources are involved in cognitive and motor control. The cortical basis of hand movements like grasping, tool use, or repetitive finger movements has been intensively investigated with functional imaging (Dettmers et al., 1995; Ball et al., 1999; Graziano et al., 2002; Lewis, 2006; Begliomini et al., 2007). However, due to the impossibility of performing larger movements in the MR scanner, less is known about the functional anatomy of locomotor control (Miyai et al., 2001; Jahn et al., 2004, 2008; Sahyoun et al., 2004). Locomotion-related activations in older adults have been particularly neglected in previous research.

In recent years, motor imagery has been established as a method to investigate cortical activations during locomotion within a PET or MRI scanner (Miyai et al., 2001; Malouin et al., 2003; Jahn et al., 2004, 2008; La Fougère et al., 2010). Imagination of movements certainly requires an additional cognitive component. Nevertheless, there are numerous studies that have confirmed that when imagining a movement similar and identical brain areas are activated as if the movement was actually being performed (Stephan et al., 1995; Jeannerod and Frak, 1999; Lotze et al., 1999; Sahyoun et al., 2004; Solodkin et al., 2004; La Fougère et al., 2010; for review, see Lafleur et al., 2002). Using near-infrared spectroscopy, Miyai et al. (2001) found that gait imagery increased activities caudally located in the supplementary motor areas (SMA) (Miyai et al., 2001). The locomotor network, as revealed by motor imagery, further includes frontal brain areas, the basal ganglia, brainstem, tegmentum, and cerebellum (Jahn et al., 2008; La Fougère et al., 2010).

\section{MOVEMENT AUTOMATION: EXPERT-NOVICE AND LEARNING STUDIES}

It seems reasonable to assume that well-learned or regularly executed movements require less cognitive control than new or rarely performed movements. Thus expert-novice and learning studies can shed light on the effect of motor status on brain activation patterns during motor performance. It has been shown that motor status might influence brain activation during the performance of a well-learned motor task such that different networks are activated in experts and novices (Ross et al., 2003; Wei and Luo, 2010). Other studies revealed more focused motor cortex activations for well trained and automated movements in expert relative to amateur musicians or golf players, respectively (Lotze et al., 2003b; Ross et al., 2003). Moreover, in contrast to amateurs, professional musicians were able to allocate additional resources to the cognitive control and emotional interpretation of the imagined piece of music (Lotze et al., 2003a).
Even motor learning studies have been performed using motor imagery. Lacourse et al. (2005) compared the functional neuroanatomy associated with executed and imagined hand movements in novel and skilled learning phases and revealed significantly greater activation for the novel imagined than the skilled imagined movement in frontal premotor and motor regions bilaterally, as well as bilateral in the inferior posterior parietal and ipsilateral in the temporal lobe. Olsson et al. (2008) investigated differences in brain activity between a group of skilled high jumpers and novices when performing motor imagery of a high jump. Whereas skilled high jumpers primarily activated well established internal motor representation (e.g., premotor cortex and cerebellum), novices also activated external visual patterns in the superior occipital cortex (Olsson et al., 2008).

Thus, well-learned and automated tasks require less cognitive control and less visual-spatial processing, but more focused motor cortex activation.

\section{STUDY AIMS}

Based on the above-mentioned studies, we aimed to investigate brain activation patterns in lower extremity motor tasks of different complexity and requiring different levels of conscious cognitive supervision (walking forward and backward). Controlling gait and balance during walking seems to be more demanding for older than for younger adults (Laufer, 2005). Nevertheless, the regularly used and trained forward walking task should be easier to perform than the rather unusual and less trained backward walking task. Thus we chose these two tasks as examples of different task complexities. Brain activation patterns were analyzed to examine (1) if brain activation differed in forward and backward walking and (2) if high- and low-fit participants (assessed by a motor test battery) differed in the cortical resources expended to imagine the forward and backward walking tasks. We were particularly interested in those frontal regions that have been shown to be related to cognitive functions. In accordance with the cross-domain resource competition theory (Baltes et al., 2006) we expected that high-fit older adults require fewer cognitive resources for locomotion (in simple and complex tasks) and show a higher level of automation. This might leave more resources available to perform a concurrent cognitive task.

More specifically, we hypothesized that older participants with a higher motor status should need less cognitive control of walking movements and thus should have stronger but more focused activations in primary motor and premotor cortical areas. A lower motor status should require more cognitive and attentional control and thus bind more resources indicated by activations in dorsolateral prefrontal and middle frontal regions.

\section{MATERIALS AND METHODS PARTICIPANTS}

Seventy-two participants were recruited from a member register of a German health insurance company (DAK) and divided into high-fit and low-fit subjects, accordingly (see below). Participants were excluded from the study if they had a history of cardiovascular diseases, any neurological disorder (e.g., self-report of neurological diseases such as brain tumor, Parkinson's disease, stroke), any other motor or cognitive restriction (a score of less than 27 in the 
Mini Mental Status Examination (MMSE, Folstein et al., 1975), or metal devices in the body. All subjects participated voluntarily in the study and provided written informed consent to the procedures of the study, which was approved by the ethics committee of the German Psychological Society. The study conforms to the Code of Ethics of the World Medical Association (Declaration of Helsinki). For data analysis, participants were further excluded if they had incomplete MRI or motor data, had not answered the movement imagery questionnaire or reached insufficient imagery scores (see below).

Fifty-one older adults between 64 and 79 years of age (mean age: 68.73 years, $\mathrm{SD}=3.26 ; 38$ female) were included in the final data analysis. Participants were tested for normal vision (Freiburg Visual Acuity Test. Bach, 2007) and hearing (Simultaneous auditory thresholds at multiple frequencies for both ears, presentation software: Neurobehavioral Systems, Albany, Canada. Yund, 2003), subjective and objective health as well as cognitive functioning. Means and standard deviations as a function of motor status are shown in Table 1.

\section{ASSESSMENT OF MOTOR STATUS}

The motor status of the participants was assessed by a heterogenous motor test battery. The test battery comprised tests of speed (hand tapping, Oja and Tuxworth, 1995; feet tapping, Voelcker-Rehage and Wiertz, 2003; agility test, Adrian, 1981; and chair stand test, Jones et al., 1999), balance (backward beam walk, Kiphard and

Table 1 | Demographic information of participants in the high and low

fitness groups. Means ( $M$ ) and standard deviations (SD) for age (average

age in years), gender (proportion of female participants), education (years of education), IQ, subjective health, objective health (number of diseases), hypertension (proportion of participants who had been diagnosed with hypertensive disorder), and fitness index.

\begin{tabular}{lllllll}
\hline & \multicolumn{2}{c}{$\begin{array}{c}\text { High motor } \\
\text { status }\end{array}$} & & \multicolumn{2}{c}{$\begin{array}{c}\text { Low motor } \\
\text { status }\end{array}$} \\
\cline { 2 - 3 } \cline { 5 - 7 } $\begin{array}{l}\text { Demographic } \\
\text { factor }\end{array}$ & $\boldsymbol{M}$ & SD & & $\boldsymbol{M}$ & SD & $\boldsymbol{P}$ \\
\hline Age & & & & & \\
Gender & 67.79 & 2.91 & & 69.95 & 3.35 & 0.017 \\
Education & 75.09 & & & 72.70 & & 0.801 \\
IQ & 12.52 & 3.01 & & 12.64 & 2.54 & 0.882 \\
Subjective health & 3.55 & 0.87 & & 3.41 & 0.80 & 0.550 \\
Objective health & 1.48 & 1.27 & & 1.95 & 1.59 & 0.244 \\
Hypertension & 31.00 & & & 50.00 & & 0.174 \\
Fitness index & 1.68 & 1.52 & & -2.13 & 2.35 & $<0.001$ \\
\hline
\end{tabular}

10 was measured with a test battery from the Berlin aging study (cf. Li et al., 2004): seven tests were used reflecting five primary intellectual abilities: (a) perceptual speed, measured by the mean performance of Digit-Symbol Substitution and Identical Picture tests, (b) reasoning, measured by the mean performance of tests of Figural Analogies and Letter Series, (c) memory, measured by Paired Associate, (d) verbal fluency, measured by the test of naming names of animals, and (e) verbal knowledge, measured by Vocabulary test. Performance scores were transformed into $T$ scores $(M=50, S D=10)$ and a mean 10 -score was calculated.

$P$-values of t-tests for independent samples and Mann-Whitney U-tests, respectively.
Schilling, 1974; one-leg stand with eyes open and closed, Ekdahl et al., 1989), fine coordination (Purdue Pegboard test, Tiffin and Asher, 1948), flexibility (shoulder flexibility, Rikli and Jones, 1999), and physical fitness (strength: grip force, Igbokwe, 1992; cardiovascular fitness: submaximal graded exercise test using spiroergometry, modified Porszasz protocol, Porszasz et al., 2003).

The hand tapping test required participants to move the dominant hand back and forth over the non-dominant hand placed on a table as quickly as possible [time needed for 25 full cycles (50 taps) was measured]. The feet tapping test required participants to tap with both feet simultaneously in a sitting position across a marker on the floor in front of them (number of taps within $20 \mathrm{~s}$ were counted). The agility test was conducted on a 31-ft course marked by traffic cones. The subjects were required (starting from a seated position) to rise from a chair, walk around a cone to the right, return to be fully seated on the chair, rise and walk around another cone the same distance to the left of the chair (time to complete the course two times in a row was measured). In the chair stand test the participants stood completely up from a sitting position, then completely back down for $30 \mathrm{~s}$. The arms were crossed at the wrists and held close to the chest (number of complete chair stands was counted). The beam walk test required participants to walk backward on three balance beams with widths of $6,4.5$, and $3 \mathrm{~cm}$. The number of steps on each beam was counted (maximum eight steps per beam). In the one-leg stand participants were asked to stand on one leg with the other slightly flexed and looking straight ahead. Compensatory movements of arms and lifted legs, but not of the standing leg were accepted (duration of standing in seconds (maximum 20 s) was noted). The one-leg stand with eyes closed was performed accordingly. In the shoulder flexibility test the participants were asked to move their hands as close together as possible by holding a stick behind the back (minimum distance between the hands was measured).

To measure maximal grip strength (in kilograms, grip dynamometer TKK 5101), the handle was adjusted to fit the hand size of the participant, the elbow was required to be in a fully extend position, and the arm was not to be pressed against the body. During spiroergometry participants completed a submaximal graded exercise test using a ramp-like treadmill protocol (modified Porszasz protocol, Porszasz et al., 2003) on a Lode Valiant motor-driven treadmill with electrocardiography activity monitored by a 10-lead fully digital stress system (Kiss, GE Medical Systems). Oxygen uptake volume $\left(\mathrm{VO}_{2}\right)$ was measured breath-by-breath and in data analysis the mean $\mathrm{VO}_{2}$ of the highest complete performance level achieved by the participant was used as reported elsewhere (Voelcker-Rehage et al., 2010).

For the dimensions speed, balance, and physical fitness the scores of the respective subtests were averaged and an overall index for the motor status was calculated using a sum score of the five fitness dimensions. Participants were then divided by median, split into high-fit and low-fit subjects, accordingly.

\section{MOVEMENT IMAGERY \\ Motor imagery tasks}

Participants performed four imagery tasks: (i) walking forward, (ii) walking backward, (iii) standing still and relaxed as baseline condition, and (iv) counting backward from 100 as a no-movement 
control condition. Outside the MR scanner, before the test sessions, a standardized description of the imagery tasks was provided and participants completed a task familiarization exercise. Participants were trained in the two experimental motor tasks (walking forward and backward) and the two control tasks (standing and counting backward). First, participants performed the real tasks and the imagination on a treadmill (Model Lode Valiant, Groningen Nederland) for at least 5 min each. Walking forward was trained with an individual moderate speed $(2.5-3.5 \mathrm{~km} / \mathrm{h})$ and easy swinging of the arms, while walking backward was trained in tandem walk $(1 \mathrm{~km} / \mathrm{h})$. We used a treadmill instead of real-world walking to provide constant visual input and ground.

All participants were already familiar with walking on a treadmill, i.e., they had at least 10-20 min experience with it and felt comfortable on the treadmill. After executing the real and imagined movements on the treadmill, participants trained their imagination of these movements (including gait initiation) in a horizontal position in periods of $20 \mathrm{~s}$ each until they felt well experienced with the tasks. Participants were instructed to close their eyes and to use a first-person perspective to perform the imagery tasks.

Then, on another day, participants first repeated the movement imagination outside the MRI scanner until they felt confident again and then performed the tasks within the scanner (first-person perspective, eyes closed). Each condition was performed six times for $20 \mathrm{~s}$ each in a randomized order without any break between the blocks.

\section{Assessment of movement imagery}

Clarity and intensity of motor imagery was assessed by the Movement imagery questionnaire MIQ-R (Hall and Martin, 1997). After the practice and scan session participants were asked, for each single movement, to indicate on a scale from 1 (very bad) to 7 (very good) how clear and intensive they could feel the movement and how vivid the inner picture of themselves was during the imagination process. Eight subjects had to be excluded because they revealed insufficient motor imagery (a score less than 4 in vividness of the walking backward condition). Independent samples $t$-test revealed no significant difference between high- and low-fit subjects for each of the tasks for vividness and intensity [always $t(48)<0.68, P>0.01]$.

\section{Functional MRI}

We used a 3T headscanner (Siemens Magnetom Allegra, Erlangen, Germany). Functional MRI scans were performed in randomized block design with six sequences of $20 \mathrm{~s}$ for each of the four conditions. In total, this resulted in $120 \mathrm{~s}$ per condition and $8 \mathrm{~min}$ per run. A T2*-weighted gradient echo multislice sequence (EPI, TR $2500 \mathrm{~ms}$, TE $60 \mathrm{~ms}$, voxel size $3 \mathrm{~mm} \times 3 \mathrm{~mm} \times 3 \mathrm{~mm}$, matrix $64 \times 64$ ) was used to acquire 48 slices covering the whole brain and the cerebellum. One run per subject was performed consisting of 190 volumes (two additional volumes at the beginning of each run were discarded to avoid saturation artifacts). Additionally, a highresolution T1-weighted anatomical 3D-dataset containing 172 sagittal slices $\left(1 \mathrm{~m}^{3} \times 1 \mathrm{~m}^{3} \times 1 \mathrm{~m}^{3}\right)$ was acquired for each subject.

Group statistics, pre-processing and statistical analysis of the data were carried out with Brainvoyager QX (Brain Innovation BV, Maastricht, Netherlands). All images were realigned to the first image of the time series for movement correction. The first image of each run was co-registered to the structural image, which was then normalized to standard Talairach space. Finally, the EPI images were spatially smoothed using a $6 \mathrm{~mm}$ (full width half maximum) Gaussian kernel. Each subject's dataset was highpass (cut-off period $240 \mathrm{~s}$ ) and lowpass filtered (2.8 s).

A general linear model (GLM) was applied to the time course of each voxel (Worsley and Friston, 1995). The BOLD responses were modeled with a delayed box-car function convolved with a canonical hemodynamic response. A random effects analysis was performed, considering the inter-subject variability; the results can therefore be generalized to other samples. In the random effects analysis, on the first level, weighted beta-images were computed for every condition (forward walking, backward walking, and counting backward from 100) relative to baseline (standing still). These individual beta values were then entered into a second level RFX analysis to obtain activations for the different task conditions. $P$-values were corrected for multiple comparisons by false discovery rate (FDR, $P<0.05)$ and cluster threshold estimation using Monte Carlo simulations (alpha level $<0.05$; Forman et al., 1995; Goebel et al., 2006). Here we report only the results for the walking conditions but not for the counting condition ${ }^{1}$. Shared and unique activations for the two conditions backward and forward walking were calculated by contrasting these two conditions with each other and by conjunction analysis. Results of high- and lowfit participants were contrasted independently for the two walking conditions. For contrast and conjunction analysis we relaxed the threshold to $P<0.01$, again corrected for multiple comparisons by cluster threshold estimation.

We extracted the average time course of the BOLD response (change in BOLD signal during motor imagery) in those regions of interest that revealed significant differences between high- and low-fit participants. Differences between the two groups were tested for significance by Student's $t$-tests for independent samples.

\section{RESULTS GENERAL EFFECTS OF BACKWARD VERSUS FORWARD WALKING}

Imagination of backward and forward walking elicited activations in a widely distributed cortical and subcortical network (Figure 1 and Table 2). Overlapping activations for both types of walking were found in the primary motor cortex and the SMA as well as in the cerebellum and left insula. However, activations were larger for backward walking in the cortical motor areas, particularly the right motor cortex, and for forward walking in the cerebellum and insula. Additional activations for backward but not forward walking were induced in the superior parietal cortex and precuneus, thalamus, putamen and caudate nucleus. Activations for forward but not backward walking were found in the anterior part of the cerebellum extending into the brainstem only (Figure 1). Decreased activation was found in the superior temporal gyrus, anterior cingulate, caudatum, parahippocampal gyrus, and the superior frontal gyrus (frontal eye field) for forward but not backward walking (Table 2).

${ }^{1}$ There was a slight but significant difference in age between the groups of high- and low-fit participants (cf. Table 1). However, covariate analysis revealed no correlation between age and brain activation during imagination of walking (at $P<0.05$, corrected by FDR) and thus we ignored this difference. 

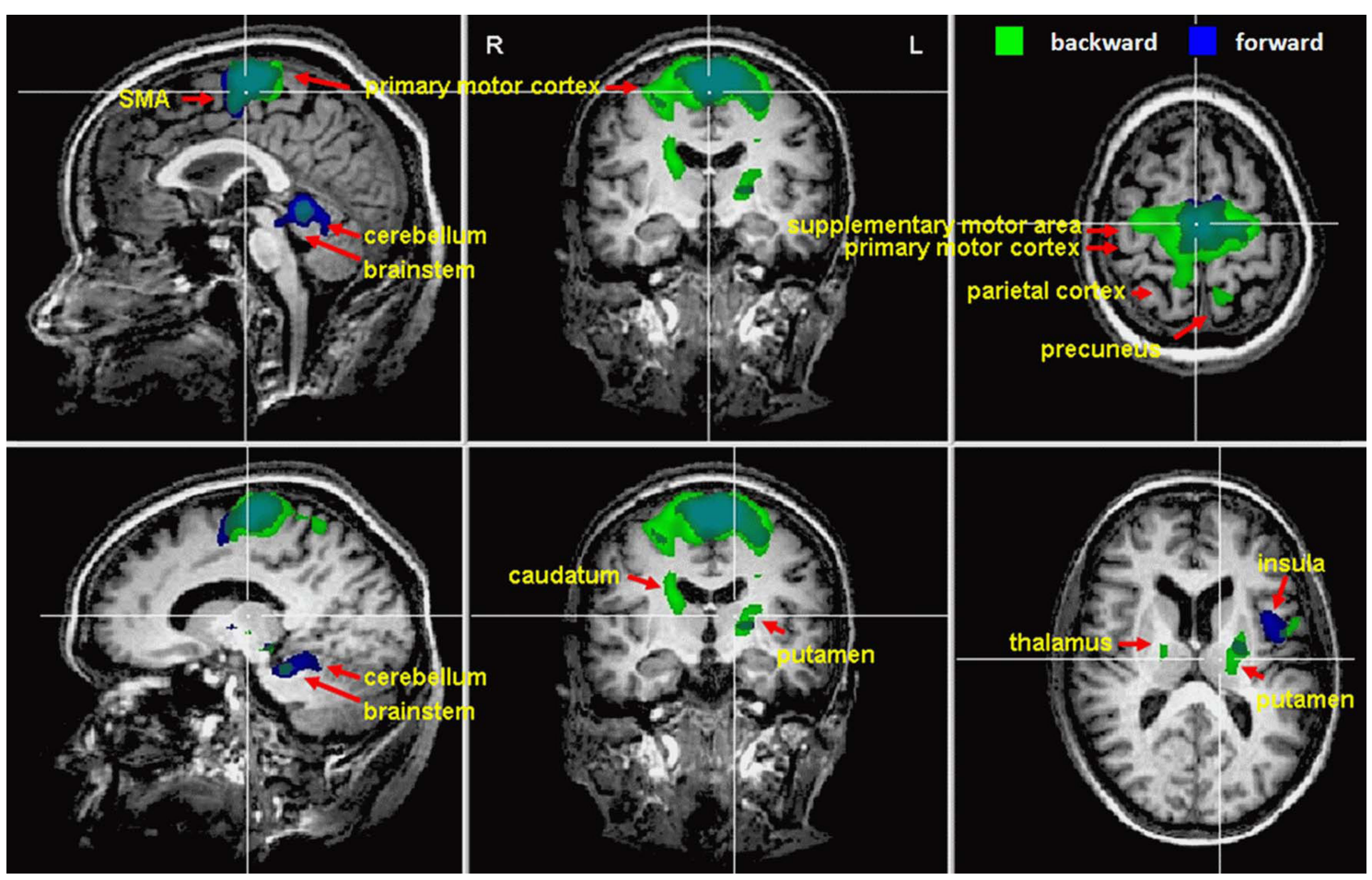

FIGURE 1 | Cortical activations during motor imagery of forward (blue) and backward (green) walking are overlaid on example anatomical slices from one individual (cf. Table 2). Overlapping regions are shown in blue-green. Only significant activations are shown with $P$-values corrected for multiple comparisons by false discovery rate (FDR, $P<0.05)$ and cluster threshold estimation using Monte Carlo simulations (alpha level $=0.05$ ).
Contrast and conjunction analyses confirmed these results. Contrasting imagination of backward and forward walking revealed unique activations for the imagination of backward walking in the middle frontal and cingulated gyrus as well as the superior parietal lobule, bilaterally, the left thalamus, right insula and precuneus, and the basal ganglia (left putamen, right claustrum and caudate). Additional activation was found in the cerebellum for the imagination of forward as compared to backward walking (cf. Figure 2 and Table 3). Conjunction analysis revealed joint activations in the left medial and superior frontal cortex, insula, and putamen and bilaterally in the cerebellum (cf. Figure 2 and Table 4). Joint inhibition was found in the right middle frontal gyrus, precuneus, and cuneus.

\section{EFFECT OF MOTOR STATUS ON BRAIN ACTIVATION DURING MOVEMENT IMAGERY}

In the next step we analyzed differences in brain activation between high-fit and low-fit participants during imagination of forward and backward walking. During imagination of forward walking high-fit as compared to low-fit participants revealed more activation in the left inferior frontal cortex and anterior insula as well as the right inferior parietal cortex. Less activation was found in the left posterior insula, middle temporal gyrus bilaterally and the left amygdala (Figure 3 and Table 5).

In the backward walking condition, motor high-fit persons as compared to low-fit participants showed larger activation patterns and higher BOLD signals in motor-related areas (ventral premotor cortex and SMA). Low-fit participants, however, had exclusive activations in the right dorsolateral prefrontal cortex and left middle temporal cortex (Figure 4 and Table 5).

As we were mainly interested in the effect of movement complexity, we examined the BOLD responses in these regions more closely for both walking conditions. Inspection of BOLD time course revealed that in the SMA and ventral premotor cortex, high-fit participants showed significantly stronger activations as compared to low-fit subjects throughout the imagination period; activity of low-fit subjects declined earlier, particularly for the imagination of backward walking (Figure 5). For both groups of subjects, BOLD signal decreased earlier for the forward than the backward condition (Figure 5). Activity in the DLPFC rose in the low-fit participants for the backward condition in the middle of the imagination period (significant group differences) indicating more attention effort during the later phase of the task.

\section{DISCUSSION}

We examined brain activation patterns during the imagination of simple, usually automated (forward walking) and more complex or rather unusual and thus more difficult (backward walking) lower extremity movements in high- and low-fit older adults. We confirmed our hypothesis that imagination of backward walking requires more cognitive control as compared to forward walking, particularly in participants with a low motor status. This study was intended as a first step to investigate if and how fitness 
Table 2 | Talairach coordinates, $\boldsymbol{t}$ - and $\boldsymbol{P}$-values, and voxel numbers of significant regions of interest for imagination of forward and backward walking.

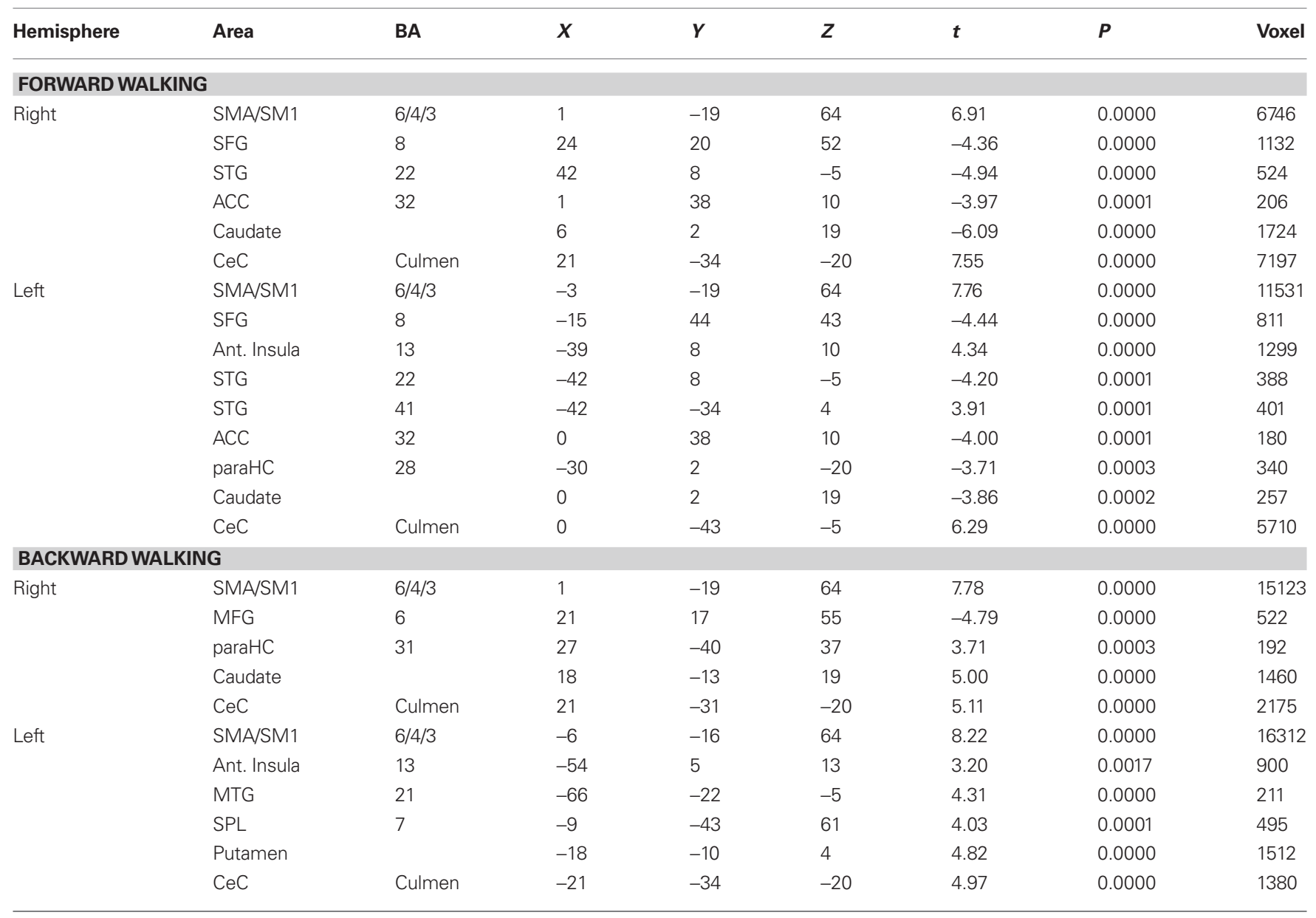

Negative t-values indicate decreased activation during imagination.

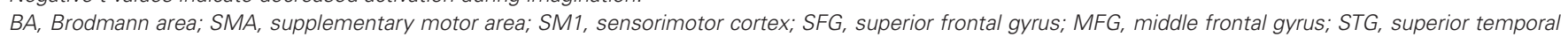
gyrus; MTG, middle temporal gyrus; ACC, anterior cingulate cortex; paraHC, parahippocampal gyrus; CeC, cerebellar cortex.

training interventions might be beneficial for older adults by attenuating the effects of brain aging on the cognitive control of movements.

\section{BRAIN ACTIVATION DURING IMAGERY OF LOCOMOTION}

As shown by many others (Miyai et al., 2001; Jahn et al., 2004, 2008; Sahyoun et al., 2004; Solodkin et al., 2004; La Fougère et al., 2010), both types of walking imagination tasks activated those regions in the brain that are known to also be involved in the corresponding executed movements: dorsal premotor cortex, primary motor cortex, dorsal and inferior parietal cortex, left insula, basal ganglia (putamen and caudate), thalamus, cerebellum, and brain stem.

Furthermore, we found larger and additional activations during the imagination of walking backward as compared to forward walking in various brain regions. Whereas such increased activation in motor cortex, inferior parietal cortex, thalamus and basal ganglia might indicate that more difficult or less practiced motor tasks require more resources (Malouin et al., 2003; Lacourse et al., 2005), increased activation of the superior parietal cortex suggests that purely kinesthetic imagery is supported by visual imagery during backward walking (Sacco et al., 2006; Guillot et al., 2009). While there were nearly overlapping activations in the left motor cortex for backward and forward walking, it is worth noting that, activations in the right motor cortex were much larger during the imagination of backward walking. Learned motor programs for both the left and right body side are stored in the left hemisphere irrespective of the task (Halsband and Lange, 2006). The larger activations in the cerebellum and brainstem might reflect a higher level of automation of forward walking. Right motor cortex activation indicates that walking backward is a less automated, rather unusual task and of higher complexity in that the exact placement of the feet (during tandem walk) needs to be controlled (Malouin et al., 2003; Wu et al., 2004). Practicing and automation of movements therefore seems to help to reduce the brain resources needed for execution and control of these movements, that is, less frontal brain resources are used and in turn might be available for cognitive tasks.

\section{MOTOR IMAGERY VERSUS REAL MOVEMENTS}

It might be argued that motor imagery differs from pure motor tasks in respect to the quality of brain processing and the amount of brain resources required. Indeed, motor output has to be inhibited rather 

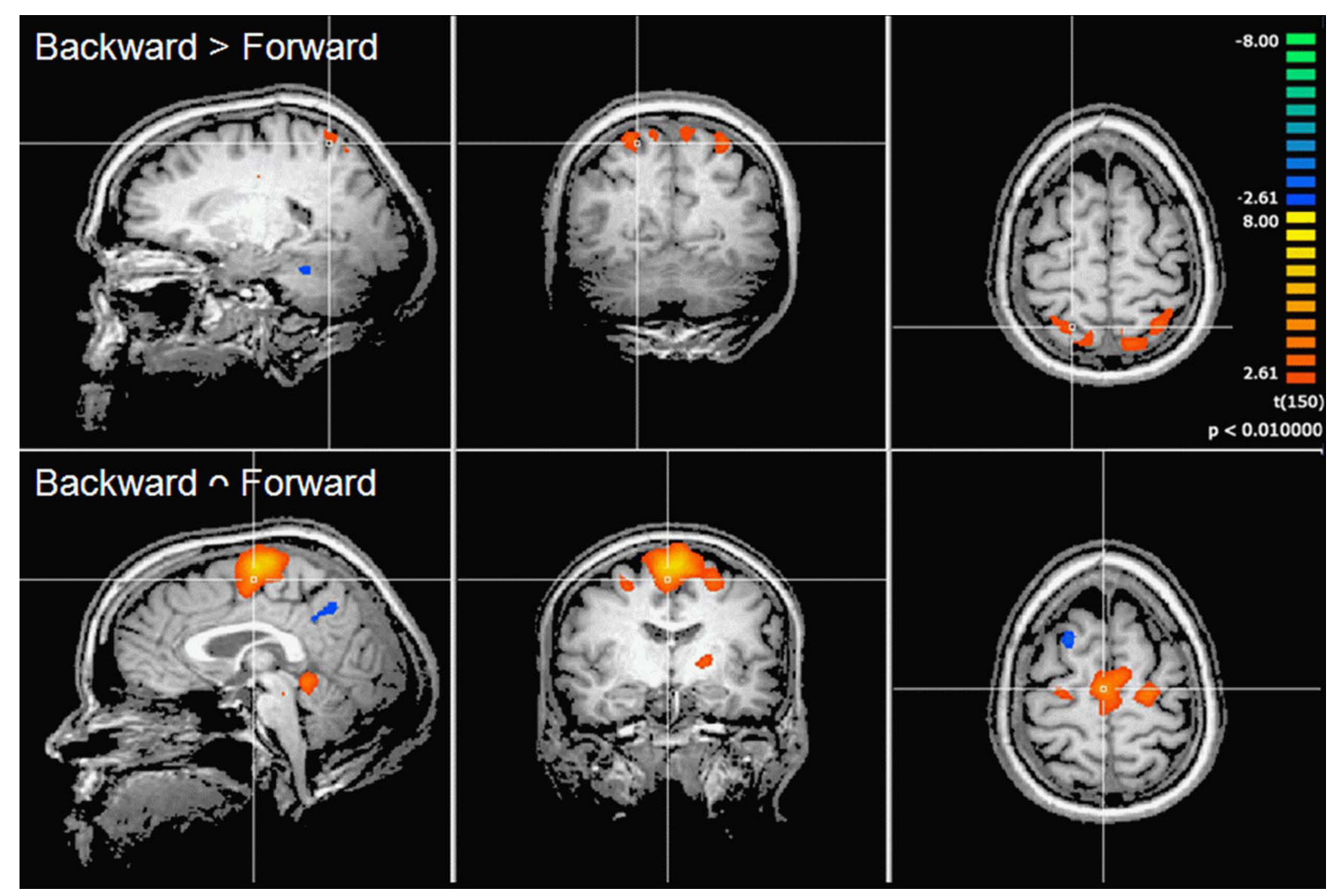

FIGURE 2 | Cortical activations during motor imagery overlaid on example anatomical slices from one individual. Upper panel: contrast of backward versus forward walking with yellow to orange indicating backward $>$ forward and blue to green indicating forward > backward (cf. Table 3). Lower panel: conjunction analysis of backward and forward walking with excitation relative to baseline (standing still) shown in yellow/orange and inhibition shown in blue/ green (cf. Table 4). P-values corrected for multiple comparisons by cluster threshold estimation using Monte Carlo simulations (alpha level $=0.05$ ).

Table 3 |Talairach coordinates, $\boldsymbol{t}$ - and $\boldsymbol{P}$-values, and voxel numbers of significant regions of interest resulting from contrast analysis for imagination of backward versus forward walking (upper part) and forward versus backward walking (lower part), respectively (cf. Figure 2, upper panel).

\begin{tabular}{|c|c|c|c|c|c|c|c|c|}
\hline Hemisphere & Area & BA & $x$ & $Y$ & $z$ & $t$ & $\boldsymbol{P}$ & Voxel \\
\hline \multicolumn{9}{|c|}{ BACKWARD > FORWARD } \\
\hline \multirow[t]{4}{*}{ Left } & MFG & 6 & -24 & -10 & 67 & 2.88 & 0.0023 & 7 \\
\hline & $\mathrm{ACC}$ & 24 & -15 & -10 & 34 & 3.32 & 0.0006 & 30 \\
\hline & $\mathrm{SPL}$ & 7 & -12 & -49 & 64 & 4.16 & 0.0000 & 171 \\
\hline & MFG & 10 & -36 & 44 & 7 & 3.05 & 0.0013 & 18 \\
\hline \multirow[t]{5}{*}{ Right } & MFG & 6 & 24 & -13 & 58 & 2.90 & 0.0021 & 17 \\
\hline & $\mathrm{ACC}$ & 24 & 18 & -13 & 34 & 3.21 & 0.0008 & 14 \\
\hline & Insula & 13 & 33 & 26 & 19 & 3.62 & 0.0002 & 62 \\
\hline & STG & 22 & 42 & 11 & -8 & 3.44 & 0.0004 & 9 \\
\hline & Prec./PoCG & 31 & 24 & -43 & 34 & 2.94 & 0.0019 & 9 \\
\hline Right & $\mathrm{CeC}$ & Culmen & 21 & -40 & -20 & 3.26 & 0.0007 & 11 \\
\hline
\end{tabular}

BA, Brodmann area; PrCG, precentral gyrus; SPL, superior parietal lobule; MFG, middle frontal gyrus; ACC, anterior cingulate cortex; STG, superior temporal gyrus; Prec., precuneus; PoCG, postcentral gyrus. 
Table 4 |Talairach coordinates, $t$ - and $\boldsymbol{P}$-values, and voxel numbers of significant regions of interest resulting from conjunction analysis for imagination of backward and forward walking relative to baseline (standing still) (cf. Figure 2, lower panel).

\begin{tabular}{|c|c|c|c|c|c|c|c|c|}
\hline Hemisphere & Area & BA & $x$ & $Y$ & $z$ & $t$ & $P$ & Voxel \\
\hline \multicolumn{9}{|l|}{ EXCITATION } \\
\hline \multirow[t]{4}{*}{ Left } & MeFG/SFG & 6 & 0 & -19 & 64 & 7.34 & 0.0000 & 799 \\
\hline & Insula & 13 & -36 & 8 & 10 & 3.55 & 0.0003 & 22 \\
\hline & Putamen & & -21 & -7 & 7 & 4.89 & 0.0000 & 38 \\
\hline & $\mathrm{CeC}$ & Culmen & -18 & -34 & -17 & 5.14 & 0.0000 & 171 \\
\hline \multirow[t]{3}{*}{ Right } & MFG & 8 & 24 & 20 & 49 & -3.90 & 0.00007 & 40 \\
\hline & Precuneus & 7 & 3 & -55 & 37 & -3.23 & 0.0008 & 19 \\
\hline & Cuneus & 18 & 27 & -76 & 13 & -3.28 & 0.0007 & 9 \\
\hline
\end{tabular}

Negative t-values indicate decreased activation during imagination.

BA, Brodmann area; MeFG, medial frontal gyrus; SFG, superior frontal gyrus; MFG, middle frontal gyrus; CeC, cerebellar cortex.

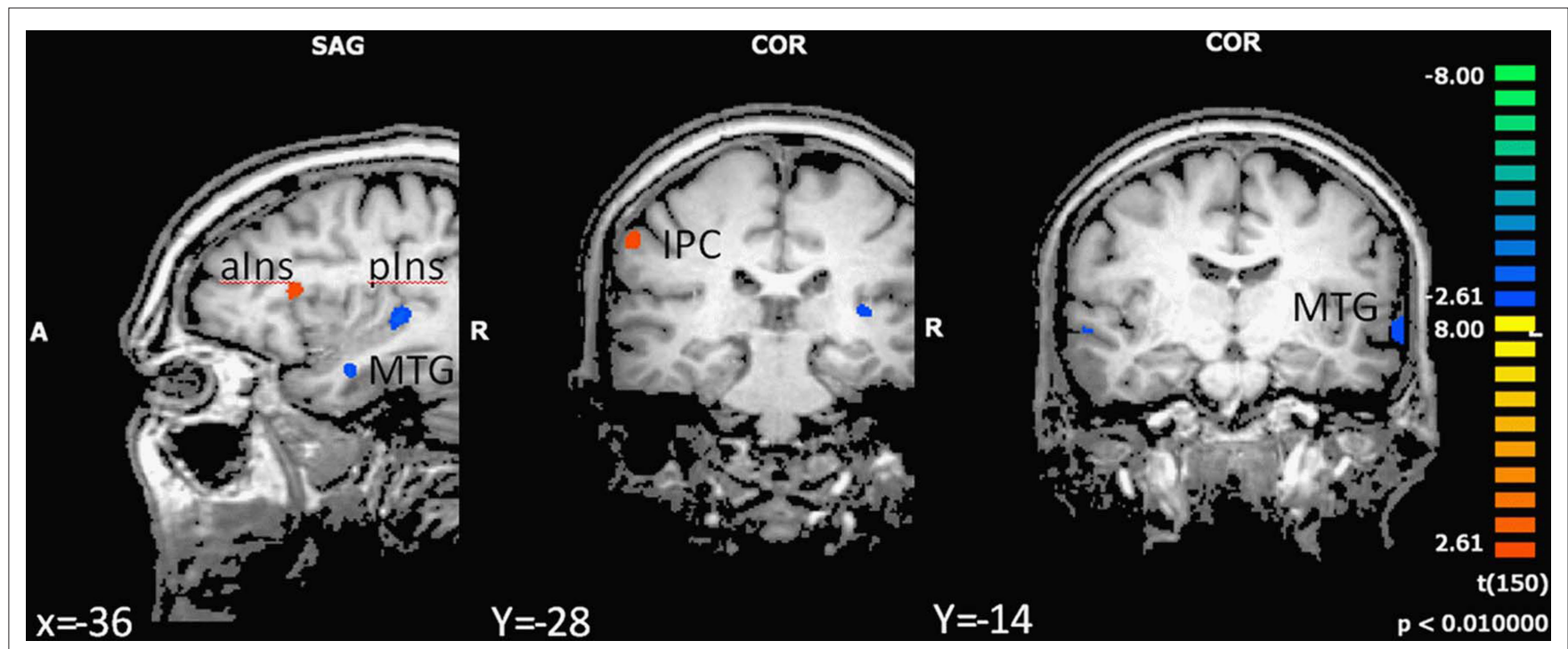

FIGURE 3 | Effect of motor status on brain activation during imagery of forward walking. Regions with significant differences for high- and low-fit participants are shown in blue to green (low fit > high fit) and orange to yellow (high fit $>$ low fit). $P<0.01$, cluster threshold level defined by Monte Carlo simulations (alpha level $=0.05$ ). MTG, middle temporal gyrus; IPC, inferior parietal cortex; DLPFC, dorsolateral prefrontal cortex; alns, anterior insula; plns, posterior insula. than evoked and the imagination of movements certainly requires an additional cognitive component. Nevertheless, numerous studies confirm the similarity of brain activation patterns between real and imagined movements (Stephan et al., 1995; Jeannerod and Frak, 1999; Lotze et al., 1999; Sahyoun et al., 2004; Solodkin et al., 2004; for review, see Lafleur et al., 2002). La Fougère et al. (2010) found slightly different activation patterns for real and imagined forward walking. Only real locomotion elicited activation in the primary motor and somatosensory cortices whereas walking imagery led to stronger activations in the supplementary motor cortex, basal ganglia and brainstem. The authors, however, attributed these differences to distinct patterns of locomotion tested: Whereas real walking was performed for 10 min with constant speed, locomotion imagery was performed similarly to our study in 20-s periods including gait initiation and velocity changes.
It is also important to distinguish between kinesthetic imagination (feeling oneself moving) and visual imagination (seeing oneself moving). Olsson et al. (2008) investigated differences in brain activity between one group of active high jumpers and one group of high jumping novices when performing motor imagery of a high jump. The results showed that active high jumpers primarily activated motor areas, e.g., premotor cortex and cerebellum. Novices activated visual areas, e.g., superior occipital cortex. These results indicate that in order to use an internal perspective during motor imagery of a complex skill, one must have well established motor representations of the skill, which then translate into an internal motor pattern of brain activity. We confirmed these results as we found a higher participation of the visual network during backward as compared to forward walking. 
Table 5 |Talairach coordinates, $\boldsymbol{t}$ - and $\boldsymbol{P}$-values, and voxel numbers of significant regions of interest for imagination of backward and forward walking in high- versus low-fit participants.

\begin{tabular}{|c|c|c|c|c|c|c|c|c|}
\hline Hemisphere & Area & BA & $x$ & $Y$ & $z$ & $\boldsymbol{t}$ & $\boldsymbol{P}$ & Voxel \\
\hline \multicolumn{9}{|c|}{ FORWARD WALKING (HIGH VERSUS LOW MOTOR STATUS) } \\
\hline Right & MTG & 21 & 60 & -7 & -2 & -3.15 & 0.001952 & 297 \\
\hline \multirow[t]{2}{*}{ Left } & Amygdala & & -21 & -4 & -23 & -3.63 & 0.000392 & 766 \\
\hline & Ant. Insula & 13 & -36 & 17 & 16 & 3.14 & 0.002003 & 305 \\
\hline \multicolumn{9}{|c|}{ BACKWARD WALKING (HIGH VERSUS LOW MOTOR STATUS) } \\
\hline \multirow[t]{2}{*}{ Right } & $\operatorname{PrCG}$ & 44 & 57 & 11 & 4 & 3.91 & 0.000138 & 776 \\
\hline & DLPFC & 6 & 51 & 14 & 44 & -3.70 & 0.0003 & 1365 \\
\hline \multirow[t]{2}{*}{ Left } & SMA & 6 & -3 & -19 & 67 & 3.55 & 0.000511 & 382 \\
\hline & MTG & 21 & -67 & -31 & 1 & -3.09 & 0.002362 & 243 \\
\hline
\end{tabular}

Negative $t$-values indicate decreased activation during imagination.

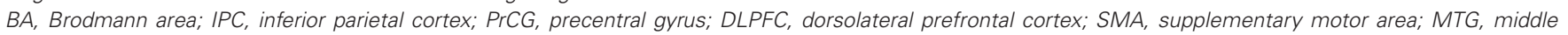
temporal gyrus.

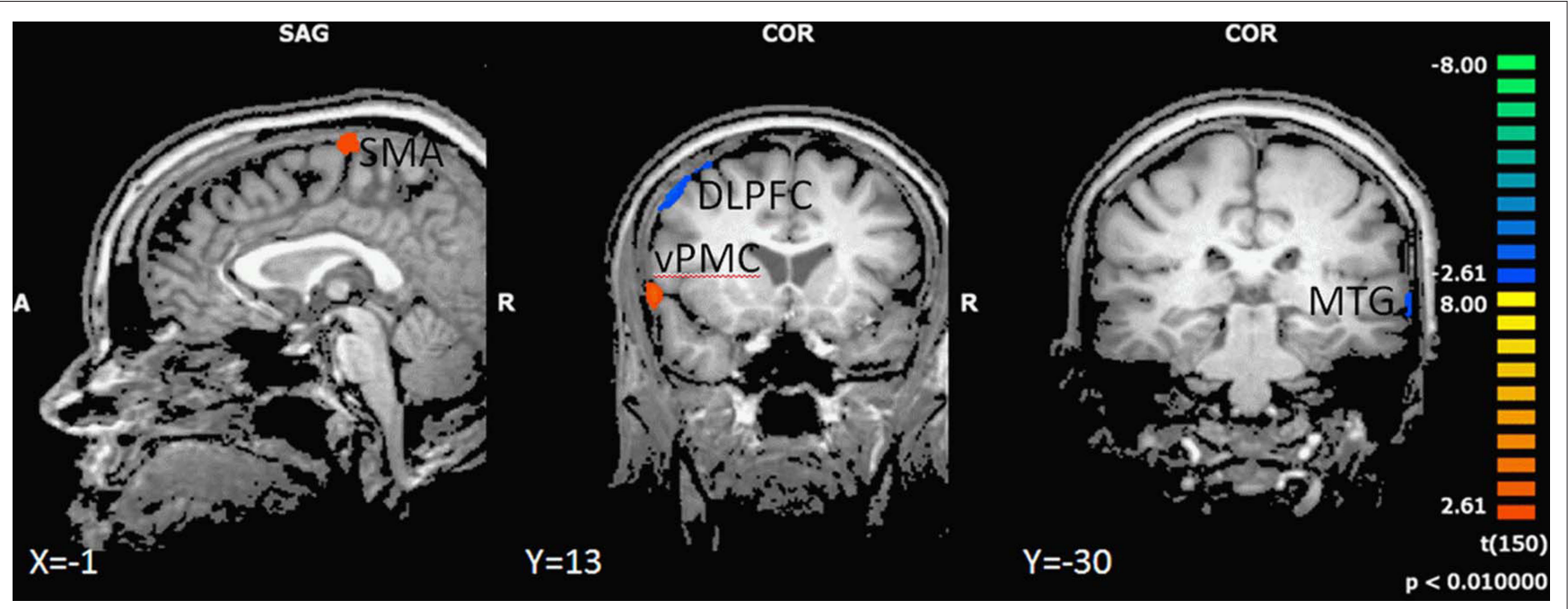

FIGURE 4 | Effect of motor status on brain activation during imagery of backward walking. Regions with significant differences for high and low motor fit participants are shown in blue to green (low fit $>$ high fit) and orange to yellow (high fit $>$ low fit). $P<0.01$, cluster threshold level defined by Monte Carlo simulations (alpha level =0.05). DLPFC, dorsolateral prefrontal cortex; SMA, supplementary motor area; vPMC, ventral premotor cortex; MTG, middle temporal gyrus.

\section{EFFECT OF MOTOR STATUS ON BRAIN ACTIVATIONS DURING MOTOR IMAGERY}

During imagination of forward walking, high-fit participants had unique activations as compared to low-fit older adults in inferior frontal and anterior insular cortex as well as inferior parietal cortex. This is in accordance with findings by Jahn et al. (2004) who found activations in these regions for imagination of walking but not running. We suggest that activations in these regions resemble normal processing during walking and do not interfere with cognitive processes. Lower brain activity in the temporal gyrus during imagination of walking forward as found for the high-fit older adults is also in accordance with the recent literature (Wagner et al., 2008). Wagner et al. (2008) interpreted deactivations in these areas as suppression of vestibular and/or visual signals. Both mechanisms - activation of the fronto-parietal network and deactivation of the temporal cortex - seem to be impaired in low-fit older adults. Due to the high degree of automation of forward walking, however, these deficits might not result in an increased activation of superior and middle frontal brain areas - as shown for backward walking.

Comparison of brain activations in high- and low-fit older adults during imagination of walking backward revealed larger activations and stronger BOLD signals in the ventral premotor cortex and SMA in high-fit persons as compared to low-fit participants. These patterns are in line with studies showing similar differences between experts and novices (Lotze et al., 2003a; Ross et al., 2003; Wei and Luo, 2010), young and older adults (Wu and Hallett, 2005) or learned and unlearned movements (Halsband and Lange, 2006). Our results indicate that high-fit participants are able 

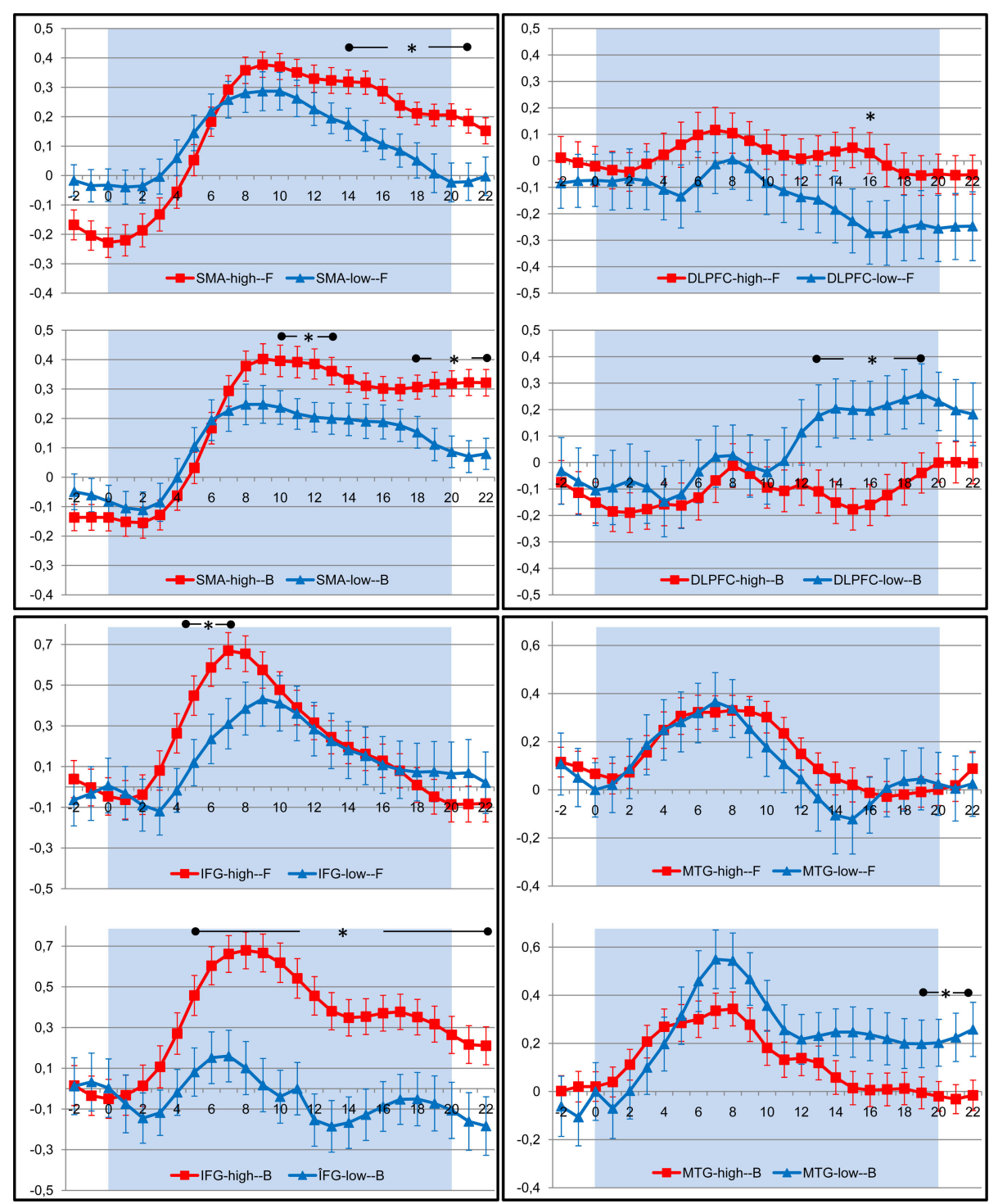

FIGURE 5 |Timecourse of BOLD response (average change in BOLD signal and standard error of the mean) in those regions of interest that revealed significant differences between high (red) and low (blue) fit participants during imagination of forward (F) and backward (B) walking. The shaded area indicates the period of imagination. SMA, supplementary motor area; DLPFC, dorsolateral prefrontal cortex; IFG, inferior frontal gyrus; MTG, middle temporal gyrus. Time points with significant differences between both groups are indicated by stars $(P<0.05$, Student's $t$-test for independent samples). to activate internal motor representations and thus walk backward more automatically than low-fit older adults. On the contrary, as revealed by unique activity in the dorsolateral prefrontal cortex for imagination of walking backwards, low-fit older adults seem to require more resources for planning and cognitive control of this task than high-fit participants. It has been suggested that an increased recruitment of dorsolateral prefrontal cortex - as shown by our low-fit participants - and also anterior cingulate cortex, reflects increasing cognitive monitoring of complex motor tasks in the elderly (Heuninckx et al., 2005). Such overactivations beyond classical motor areas support the compensation hypothesis rather than age-related dedifferentiation being causally related to performance decline (Heuninckx et al., 2008). Interestingly, the dorsolateral prefrontal activity started at the same time when activity in the SMA decreased (cf. Figure 4). Furthermore, high-fit older adults seem to have a higher "attention span," indicated by maintained activations in the SMA throughout the imagination period. Our results here support the hypothesis that a high level of motor performance corresponds with the automation of complex motor behaviors and in turn might help to free up resources (indicated by less DLPFC activation) for cognitive tasks that could be performed in parallel.

In our study, low-fit as compared to high-fit older adults had more activity in the right dorsolateral prefrontal cortex during the backward walking task. Other authors found activity during imagination of walking versus rest conditions mainly in the left dorsolateral prefrontal cortex (Malouin et al., 2003; Jahn et al., 2004). An explanation might be our chosen resting condition, 
i.e., imagery of standing still. This task in general might demand similar levels of attentional control as the walking conditions and thus contrasting walking versus rest (i.e., standing) does not reveal any additional activation in the left DLPFC. On the other hand, increasing right hemispheric prefrontal activation with lower motor status might be in accordance with the notion of compensation for age-related decline by reduced lateralization (Cabeza et al., 2004). In this logic, these compensatory right hemispheric resources have to be recruited for motor control in low-fit older adults when movements are too difficult or complex to be performed automatically. Similar dorsolateral prefrontal cortical overactivation can be found in low-fit older adults during the performance of a cognitive executive control task (VoelckerRehage et al., 2010).

The relationship between motor and cognitive performance has been studied predominantly under so-called dual-task conditions in which cognitive and motor tasks must be performed simultaneously. In these studies, effects of varying complexity in one task on performance of the other task allows for conclusions about overlapping resources, e.g., for executive control (response initiation, selective attention, working memory) (Serrien et al., 2004, 2007). Both a more detrimental effect of increasing cognitive complexity on motor performance in older as compared to younger adults (Lindenberger et al., 2000; Voelcker-Rehage et al., 2006) and effects of different degrees of motor automation on cognitive performance (Lindenberger et al., 2000; Srygley et al., 2009) were found in such studies. Walking as compared to sitting, for example, interfered negatively with subtraction and phoneme-monitoring tasks (Srygley et al., 2009) and more complex walking tracks resulted in higher dual-task costs when combined with word encoding and recall (Lindenberger et al., 2000).

\section{REFERENCES}

Adrian, M. J. (1981). "Flexibility in the aging adult," in Exercises and Aging: The Scientific Basic, eds E. L. Smith and R. C. Serfass (Hillside, NJ: Enslow Publishers), 45-58.

Bach, M. (2007). The Freiburg visual acuity test - variability unchanged by post-hoc re-analysis. Graefes Arch. Clin. Exp. Ophthalmol. 245, 965-971.

Ball, T., Schreiber, A., Feige, B., Wagner, M., Lucking, C. H., and Kristeva-Feige, R. (1999). The role of higher-order motor areas in voluntary movement as revealed by high-resolution EEG and fMRI. Neuroimage 10, 682-694.

Baltes, P. B., and Lindenberger, U. (1997). Emergence of a powerful connection between sensory and cognitive functions across the adult life span: a new window to the study of cognitive aging? Psychol. Aging 12, 12-21.

Baltes, P. B., Lindenberger, U., and Staudinger, U. (2006). "Life-span theory in developmental psychology," in Handbook of Child Development. Theoretical Models of Human Development, eds W. Damon and R.

Hausdorff et al. (2005) revealed that walking is a rather complex motor task and is associated with higher-level cognitive resources, specifically executive function (cf. also Yogev-Seligmann et al., 2008). Furthermore, Hausdorff et al. (2005) suggested that even routine walking has features of a dual or multi tasks. The described changes of older adults in motor control and sensory feedback systems might therefore lead to diminished automaticity of gait and generate a need for cognitive supervision in order to properly integrate all sensory information and regulate dynamic balance and gait. Thus, it seems plausible that a higher level of motor status might counteract this increased need for cognitive control.

Our results not only confirm that complex movements require more motor-related resources in the premotor, motor and parietal cortex than more automated movements, they also show that less-fit as compared to high-fit older adults require more effort in the cognitive control of such complex movements. It can be assumed that under real-life conditions, where motor and cognitive tasks have to be performed simultaneously, this could lead to increased competition for decreasing resources in frontal cortical areas. Therefore, although it has to be shown that the same is true for real movements, motor training interventions that help to automate movements and reduce necessary cognitive control might free such resources for cognitive tasks and help to attenuate cognitive aging. Intervention studies are therefore necessary to show such a beneficial effect of increased motor fitness on both motor and cognitive performance in old age.

\section{ACKNOWLEDGMENTS}

Our work was supported by the Robert Bosch Foundation (12.5.1366.0005.0) and the German health insurance company DAK. We thank Peter Erhard, Ekkehard Küstermann, and Melanie Löbe (Center for Advanced Imaging, University of Bremen) for support with functional MR imaging.

Silbersweig, D., Holmes, A., Ridding, M. C., Brooks, D. J., and Frackowiak, R.S. (1995). Relation between cerebral activity and force in the motor areas of the human brain. J. Neurophysiol. 74, 802-815.

Dustman, R. E., Emmerson, R., and Shearer, D. (1994). Physical activity, age, and cognitive-neurophysiological function. J. Aging Phys. Act. 2, 143-181.

Ekdahl, C., Jarnlo, G. B., and Andersson, S. I. (1989). Standing balance in healthy subjects. Scand. J. Rehabil. Med. 21, 187-195.

Erickson, K. I., and Kramer, A. F. (2009). Aerobic exercise effects on cognitive and neural plasticity in older adults. Br. J. Sports Med. 43, 22-24.

Etnier, J. L., Salazar, W., Landers, D. M., Petruzzello, S. J., Han, M., and Nowell, P. (1997). The influence of physical fitness and exercise upon cognitive functioning: a meta-analysis. J. Sport Exerc. Psychol. 19, 249-277.

Flegal, K. E., and Reuter-Lorenz, P. (2010). Aging and brain fitness (Commentary on Voelcker-Rehage et al.). Eur. J. Neurosci. 31, 165-166.

Folstein, M. F., Folstein, S. E., and McHugh, P. R. (1975). "Mini-mental state". A practical method for grading the cognitive state of patients for the clinician. J. Psychiatr. Res. 12, 189-198.

Forman, S., Cohen, J., Fitzgerald, M., Eddy, W., Mintun, M., and Noll, D. (1995). Improved assessment of significant activation in functional magnetic resonance imaging (fMRI): use of a cluster-size threshold. Magn. Reson. Med. 33, 636-647.

Goebel, R., Esposito, F., and Formisano, E. (2006). Analysis of functional image analysis contest (FIAC) data with Brainvoyager QX: from single-subject to cortically aligned group general linear model analysis and self-organizing group independent component analysis. Hum. Brain Mapp. 27, 392-401.

Graziano, M. S., Taylor, C. S., Moore, T., and Cooke, D. F. (2002). The cortical control of movement revisited. Neuron 36, 349-362.

Guillot, A., Collet, C., Nguyen, V. A., Malouin, F., Richards, C., and Doyon, 
J. (2009). Brain activity during visual versus kinesthetic imagery: an fMRI study. Hum. Brain Mapp. 30, 2157-2172.

Hall, C. R., and Martin, K. A. (1997). Measuring movement imagery abilities: a revision of the Movement Imagery Questionnaire. J. Ment. Imagery 21, 143-154.

Halsband, U., and Lange, R. K. (2006). Motor learning in man: a review of functional and clinical studies. $J$. Physiol. (Paris) 99, 414-424.

Hausdorff, J. M., Yogev, G., Springer, S., Simon, E. S., and Giladi, N. (2005). Walking is more like catching than tapping: gait in the elderly as a complex cognitive task. Exp. Brain Res. 164, 541-548.

Hedden, T., and Gabrieli, J. D. E. (2004). Insights into the aging mind: a view from cognitive neuroscience. Nat. Rev. Neurosci. 5, 87-96.

Heuninckx, S., Wenderoth, N., Debaere, F., Peeters, R., and Swinnen, S. P. (2005). Neural basis of aging: the penetration of cognition into action control. J. Neurosci. 25, 6787-6796.

Heuninckx, S., Wenderoth, N., and Swinnen, S. P. (2008). Systems neuroplasticity in the aging brain: recruiting additional neural resources for successful motor performance in elderly persons. J. Neurosci. 28, 91-99.

Hillman, C. H., Erickson, K. I., and Kramer,A.F.(2008). Be smart, exercise your heart: exercise effects on brain and cognition. Nat. Rev. Neurosci. 9, 58-65.

Igbokwe, N. U. (1992). Hand grip dynamometer and arm muscle size in teenage boys and girls. J. Phys. Educ. Sport Sci. 4, 15-19.

Jahn, K., Deutschlander, A., Stephan, T., Kalla, R., Hufner, K., Wagner, J., Strupp, M., and Brandt, T. (2008). Supraspinal locomotor control in quadrupeds and humans. Prog. Brain Res. 171, 353-362.

Jahn, K., Deutschlander, A., Stephan, T., Strupp, M., Wiesmann, M., and Brandt, T. (2004). Brain activation patterns during imagined stance and locomotion in functional magnetic resonance imaging. Neuroimage 22, 1722-1731.

Jeannerod, M., and Frak, V. (1999). Mental imaging of motor activity in humans. Curr. Opin. Neurobiol. 9, 735-739.

Jones, C. J., Rikli, R. E., and Beam, W. C. (1999). A 30-s chair-stand test as a measure of lower body strength in community-residing older adults. Res. Q. Exerc. Sport 70, 113-119.

Kahnemann, D. (1973). Attention and Effort. Englewood Cliffs, NJ: Prentice Hall.
Kiphard, E. J., and Schilling, F. (1974) Körperkoordinationstest für Kinder [Body coordination test for children]. Weinheim: Beltz.

Kramer, A. F., and Erickson, K. I. (2007). Capitalizing on cortical plasticity: influence of physical activity on cognition and brain function. Trends Cogn. Sci. (Regul. Ed. ) 11, 342-348.

La Fougère, C., Zwergal, A., Rominger, A., Forster, S., Fesl, G., Dieterich, M. Brandt, T., Strupp, M., Bartenstein, P., and Jahn, K. (2010). Real versus imagined locomotion: a [18F]-FDG PET-fMRI comparison. Neuroimage 50, 1589-1598.

Lacourse, M. G., Orr, E. L., Cramer, S. C. and Cohen, M. J. (2005). Brain activation during execution and motor imagery of novel and skilled sequential hand movements. Neuroimage 27, 505-519.

Lafleur, M. F., Jackson, P. L., Malouin, F., Richards, C. L., Evans, A. C., and Doyon, J. (2002). Motor learning produces parallel dynamic functional changes during the execution and imagination of sequential foot movements. Neuroimage 16, 142-157.

Laufer, Y. (2005). Effect of age on characteristics of forward and backward gait at preferred and accelerated walking speed.J. Gerontol. A Biol. Sci. Med. Sci. 60, 627-632.

Lewis, J. W. (2006). Cortical networks related to human use of tools. Neuroscientist 12, 211-231.

Li, K. Z. H., and Lindenberger, U. (2002). Relations between aging sensory/sensorimotor and cognitive functions. Neurosci. Biobehav. Rev. 26, 777-783.

Li, S. C., Lindenberger, U., Hommel, B. Aschersleben, G., Prinz, W., and Baltes, P. B. (2004). Transformations in the couplings among intellectual abilities and constituent cognitive processes across the lifespan. Psychol. Sci. 15, 155-163.

Lindenberger, U., and Baltes, P. B. (1994). Sensory functioning and intelligence in old age: a strong connection. Psychol. Aging 9, 339-355.

Lindenberger, U., Marsiske, M., and Baltes, P. B. (2000). Memorizing while walking: increase in dual-task costs from young adulthood to old age. Psychol. Aging 15, 417-436.

Lotze, M., Montoya, P., Erb, M.,Hulsmann, E., Flor, H., Klose, U., Birbaumer, N., and Grodd, W. (1999). Activation of cortical and cerebellar motor areas during executed and imagined hand movements: an fMRI study. J. Cogn. Neurosci. 11, 491-501.

Lotze, M., Scheler, G., Tan, H. R., Braun, C., and Birbaumer, N. (2003a). The musician's brain: functional imaging of amateurs and professionals during performance and imagery. Neuroimage 20, 1817-1829.

Lotze, M., Braun, C., Birbaumer, N., Anders, S., and Cohen, L. G. (2003b). Motor learning elicited by voluntary drive. Brain 126, 866-872.

Lustig, C., Shah, P., Seidler, R., and Reuter Lorenz, P. A. (2009). Aging, training, and the brain: a review and future directions. Neuropsychol. Rev. 19 504-522.

Malouin, F., Richards, C. L., Jackson, P. L., Dumas, F., and Doyon, J. (2003). Brain activations during motor imagery of locomotor-related tasks: a PET study. Hum. Brain Mapp. 19, 47-62.

Miyai, I., Tanabe, H. C., Sase, I., Eda, H., Oda, I., Konishi, I., Tsunazawa, Y, Suzuki, T., Yanagida, T., and Kubota, K. (2001). Cortical mapping of gait in humans: a near-infrared spectroscopic topography study. Neuroimage 14, 1186-1192.

Nieto, M. L., Albert, S. M., Morrow, L. A., and Saxton, J. (2008). Cognitive status and physical function in older African Americans. J. Am. Geriatr. Soc 56, 2014-2019.

Oja, P., and Tuxworth, B. (1995). Eurofit for Adults - Assessment of HealthRelated Fitness. Tampere: Council of Europe Publishing.

Olsson, C. J., Jonsson, B., Larsson, A., and Nyberg, L. (2008). Motor representations and practice affect brain systems underlying imagery: an FMRI study of internal imagery in novices and active high jumpers. Open Neuroimag. J. 2 , 5-13.

Porszasz, J., Casaburi, R., Somfay, A., Woodhouse, L. J., and Whipp, B. J. (2003). A treadmill ramp protocol using simultaneous changes in speed and grade. Med. Sci. Sports. Exerc. 35, 1596-1603.

Rikli, R. E., and Jones, C. J. (1999). Development and validation of a functional fitness test for communityresiding older adults. J. Aging Phys. Act 7, 129-161.

Ross, J. S., Tkach, J., Ruggieri, P. M. Lieber, M., and Lapresto, E. (2003). The mind's eye: functional MR imaging evaluation of golf motor imagery. AJNR Am. J. Neuroradiol. 24, 1036-1044.

Sacco, K., Cauda, F., Cerliani, L., Mate, D. Duca, S., and Geminiani, G. C. (2006) Motor imagery of walking following training in locomotor attention. The effect of 'the tango lesson'. Neuroimage 32, 1441-1449.

Sahyoun, C., Floyer-Lea, A., JohansenBerg, H., and Matthews, P. M. (2004) Towards an understanding of gait control: brain activation during the anticipation, preparation and execu- tion of foot movements. Neuroimage 21, 568-575.

Serrien, D. J., Ivry, R. B., and Swinnen, S. P. (2007). The missing link between action and cognition. Prog. Neurobiol. 82, 95-107.

Serrien, D. J., Pogosyan, A. H., and Brown, P. (2004). Cortico-cortical coupling patterns during dual task performance. Exp. Brain Res. 157, 79-84.

Solodkin, A., Hlustik, P., Chen, E. E., and Small, S. L. (2004). Fine modulation in network activation during motor execution and motor imagery. Cereb. Cortex 14, 1246-1255.

Srygley, J. M., Mirelman, A., Herman, T., Giladi, N., and Hausdorff, J.M. (2009). When does walking alter thinking? Age and task associated findings. Brain Res. 1253, 92-99.

Stephan, K. M., Fink, G. R., Passingham, R. E., Silbersweig, D., Ceballos-Baumann, A. O., Frith, C. D., and Frackowiak, R. S. (1995). Functional anatomy of the mental representation of upper extremity movements in healthy subjects. J. Neurophysiol. 73, 373-386.

Tiffin, J., and Asher, E. J. (1948). The purdue pegboard: norms and studies of reliability and validity. J. Appl. Physiol. 32, 234-247.

Voelcker-Rehage, C., and Alberts, J. L. (2007). Effect of motor practice on dual-task performance in older adults. J. Gerontol. B Psychol. Sci. Soc. Sci. 62, 141-148.

Voelcker-Rehage, C., Godde, B., and Staudinger, U. M. (2010). Physical and motor fitness are both related to cognition in old age. Eur. J. Neurosci. 31, 167-176.

Voelcker-Rehage, C., Stronge, A. J., and Alberts, J. L. (2006). Age-related differences in working memory and force control under dual-task conditions. Neuropsychol. Dev. Cogn. B Aging Neuropsychol. Cogn. 13, 366-384.

Voelcker-Rehage, C., and Wiertz, O. (2003). Die Lernfaehigkeit sportmotorischer Fertigkeiten im Lichte der Entwicklungspsychologie der Lebensspanne [Motor skill learning in focus of lifespan developmental psychology] Â. Bielefeld: Universitaet Bielefeld.

Wagner, J., Stephan, T., Kalla, R., Brückmann, H., Strupp, M., Brandt, T., and Jahn, K. (2008). Mind the bend: cerebral activations associated with mental imagery of walking along a curved path. Exp. Brain Res. 191, 247-255.

Wei, G., and Luo, J. (2010). Sport Expert's motor imagery: functional imaging of professional motor skills and simple motor skills. Brain Res. 1341, 52-62. 
Woo, E., and Sharps, M. J. (2003). Cognitive aging and physical exercise. Educ. Gerontol. 29, 327.

Worsley, K. J., and Friston, K. J. (1995). Analysis of fMRI time-series revisited - again. Neuroimage 2, 173-181.

Wu, T., and Hallett, M. (2005). The influence of normal human ageing on automatic movements. J. Physiol. (Lond.) 562, 605-615.

Wu, T., Kansaku, K., and Hallett, M. (2004). How self-initiated memo- rized movements become automatic: a functional MRI study. J. Neurophysiol. 91, 1690-1698.

Yogev-Seligmann, G., Hausdorff, J. M., and Giladi, N. (2008). The role of executive function and attention in gait. Mov. Disord. 23, 329-342.

Yund, E.W. (2003). Simultaneous auditory thresholds at multiple frequencies and for both ears. Arch. Neurobehav. Exp. Stimuli 69, Available at http://www.neurobs.com/ex_files/ expt_view?id=69.
Conflict of Interest Statement: The authors declare that the research was conducted in the absence of any commercial or financial relationships that could be construed as a potential conflict of interest.

Received: 31 March 2010; paper pending published: 23 April 2010; accepted: 16 August 2010; published online: 01 September 2010.

Citation: Godde B and Voelcker-Rehage C (2010) More automation and less cognitive control of imagined walking movements in high-versus low-fit older adults. Front. Ag. Neurosci. 2:139. doi: 10.3389/ fnagi.2010.00139

Copyright (c) 2010 Godde and VoelckerRehage. This is an open-access article subject to an exclusive license agreement between the authors and the Frontiers Research Foundation, which permits unrestricted use, distribution, and reproduction in any medium, provided the original authors and source are credited. 